San Jose State University

SJSU ScholarWorks

Faculty Publications, Biological Sciences

Biological Sciences

$1-1-2012$

\title{
Edaphic adaptation maintains the coexistence of two cryptic species on serpentine soil
}

J M. Yost

University of California - Santa Cruz

T Barry

San Jose State University

K M. Kay

San Jose State University

N Rajakaruna

San Jose State University, nrajakaruna@gmail.com

Follow this and additional works at: https://scholarworks.sjsu.edu/biol_pub

Part of the Plant Biology Commons

\section{Recommended Citation}

J M. Yost, T Barry, K M. Kay, and N Rajakaruna. "Edaphic adaptation maintains the coexistence of two cryptic species on serpentine soil" American Journal of Botany (2012): 890-897. https://doi.org/10.3732/ ajb.1100521

This Article is brought to you for free and open access by the Biological Sciences at SJSU ScholarWorks. It has been accepted for inclusion in Faculty Publications, Biological Sciences by an authorized administrator of SJSU ScholarWorks. For more information, please contact scholarworks@sjsu.edu. 


\title{
EDAPHIC ADAPTATION MAINTAINS THE COEXISTENCE OF TWO CRYPTIC SPECIES ON SERPENTINE SOILS ${ }^{1}$
}

\author{
Jenn M. Yost 2,5 , Teri Barry ${ }^{3}$, Kathleen M. KaY ${ }^{2}$, And Nishanta Rajakaruna ${ }^{3,4}$ \\ ${ }^{2}$ Department of Ecology and Evolutionary Biology, University of California, Santa Cruz, 1156 High St., Santa Cruz, California \\ 95064 USA; ${ }^{3}$ Department of Biological Sciences, San José State University, One Washington Square, San José, California \\ 95192 USA; and ${ }^{4}$ College of the Atlantic, 105 Eden Street, Bar Harbor, Maine 04609 USA
}

- Premise of the study: Divergent edaphic adaptation can contribute to reproductive isolation and coexistence between closely related species, yet we know little about how small-scale continuous edaphic gradients contribute to this phenomenon. We investigated edaphic adaptation between two cryptic species of California wildflower, Lasthenia californica and L. gracilis (Asteraceae), which grow in close parapatry on serpentine soil.

- Methods: We reciprocally transplanted both species into the center of each species' habitat and the transition zone between species. We quantified multiple components of fitness and used aster models to predict fitness based on environmental variables. We sampled soil across the ridge throughout the growing season to document edaphic changes through time. We sampled naturally germinating seedlings to determine whether there was dispersal into the adjacent habitat and to help pinpoint the timing of any selection against migrants.

- Key results: We documented within-serpentine adaptation contributing to habitat isolation between close relatives. Both species were adapted to the edaphic conditions in their native region and suffered fitness trade-offs when moved outside that region. However, observed fitness values did not perfectly match those predicted by edaphic variables alone, indicating that other factors, such as competition, also contributed to plant fitness. Soil water content and concentrations of calcium, magnesium, sodium, and potassium were likely drivers of differential fitness. Plants either had limited dispersal ability or migrants experienced early-season mortality outside their native region.

- Conclusions: Demonstrating that continuous habitats can support differently adapted, yet closely related, taxa is important to a broader understanding of how species are generated and maintained in nature.

Key words: aster models; Asteraceae; edaphic adaptation; habitat isolation; Lasthenia; local adaptation; plant distributions; plant soil relations; reproductive isolation; serpentine.

Ecological factors play an important role in the generation and maintenance of species (reviewed in Givnish, 2010; Sobel et al., 2010). Darwin and Wallace first provided a foundation for understanding the contributions of natural selection and adaptation to the speciation process, and yet the direct connection between adaptation and reproductive isolation is still unclear (reviewed in Coyne and Orr, 2004; Schemske, 2010; Sobel et al., 2010). As organisms adapt to the myriad ecological pressures of their environments, selection for adaptive traits can lead to uniquely adapted genotypes (e.g., Clausen et al., 1941; Kruckeberg, 1951; Sork et al., 1993; reviewed in Linhart and Grant, 1996; Kawecki and Ebert, 2004; Leimu and Fischer, 2008). Divergent adaptation can affect numerous components

${ }^{1}$ Manuscript received 30 November 2011; revision accepted 14 March 2012.

The authors thank R. Shaw and C. Geyer for assistance with aster modeling and two anonymous reviewers for contributing greatly to the outcome of the manuscript. Field and laboratory assistance was graciously provided by M. Bontrager, S. Woolhouse, J. Celis, J. Vieto, A. Philbin, C. Schmidt, J. Zaroli, J. Strommen, R. Hussey, H. Tran, P. Pants, A. Behnke, J. Knight, N. Chiariello, and Jasper Ridge Biological Preserve of Stanford University. Funding for this project was provided by the Ecology and Evolutionary Biology Department at UCSC, Hardman Native Plant Award, Northern California Botanists 2010 Scholarship, Dr. Patrick Elvander Memorial Scholarship Fund of the California Native Plant Society (Santa Cruz chapter), Alan Polanshek Research Fellowship, and Junior Faculty Career Development Grant from SJSU.

${ }^{5}$ Author for correspondence (e-mail: jmyost@ucsc.edu)

doi:10.3732/ajb.1100521 of reproductive isolation and therefore contribute to the generation and maintenance of closely related species.

Habitat isolation is the reduction in gene flow between populations caused by spatial separation of the habitats to which they are differently adapted (Mayr, 1947). Since habitat isolation precludes the opportunity for mating, it is one of the earliest acting reproductive barriers and has a disproportionately large effect on total reproductive isolation (Ramsey et al., 2003; Kay, 2006). Habitat isolation requires both divergent adaptation in habitat affinity, in which migrants between habitats are selected against, and a reduction in the likelihood of mating for individuals living in the different habitats. On a landscape scale, habitat isolation can maintain allopatric ranges when successful expansion into another species' range is prevented (i.e., ecogeographic isolation, Ramsey et al., 2003; Angert and Schemske, 2005). On a local scale, within the range of normal dispersal, habitat isolation can facilitate sympatric or parapatric coexistence of close relatives (McNeilly and Antonovics, 1968; Gardner and MacNair, 2000; Sambatti and Rice, 2006; Matute et al., 2009).

Although it is clear that edaphic environments vary over small spatial scales (van der Putten et al., 2004) and can act as agents of divergent selection (Ettema and Wardle, 2002; Rajakaruna, 2003, Baythavong and Stanton, 2010), previous investigations of small-scale habitat isolation typically have considered taxa that occur on and off discrete soil types (e.g., serpentine, mine tailings). In these cases, plants occur well within mating distance of each other but are maintained as genetically distinct populations due to low fitness on the adjacent harsh soil (e.g., McNeilly, 1968; McNeilly and Antonovics, 1968; Antonovics and 
Bradshaw, 1970; Searcy and Macnair, 1993; Gardner and MacNair, 2000; Sambatti and Rice, 2006; Wright et al., 2006; Baythavong and Stanton, 2010). For example, serpentine soils often provide highly divergent habitats that impose strong selection for tolerance even in the face of gene flow from nontolerant populations (reviewed in Kruckeberg, 1984; Brady et al., 2005; O'Dell and Rajakaruna, 2011). Studies on contrasting soil types suggest that adjacent discrete habitats can drive or maintain divergence (Harrison et al., 2000; Anacker et al., 2011), but the contribution of continuous differences in habitat to reproductive isolation, especially over small scales, is much less understood.

To address the degree over which small scale continuous edaphic gradients can contribute to habitat isolation between closely related species, we investigated the coexistence of two nearly indistinguishable species of Lasthenia (Asteraceae) on a serpentine hillside. The parapatric distribution of Lasthenia gracilis (DC.) Green and L. californica DC. ex Lindl. has been stable for at least 30 years (Rajakaruna and Whitton, 2004; Bohm and Rajakaruna, 2006), and hybrids are rarely found, although they can be created in the greenhouse (J. M. Yost, unpublished data). Habitat isolation might be playing an important role in limiting gene flow between these taxa, since other more obvious reproductive barriers are unlikely and the species occur within such close proximity (inches from one another). Although many soil variables important for plant growth vary continuously across the ridge, spatially intensive sampling has failed to find any abrupt differences in soil characters that might be used to define the species' edaphic niches (Rajakaruna and Bohm, 1999). Rajakaruna and Bohm (1999) found that the bottom of the ridge is wetter and more ionically extreme (higher concentrations of toxic ions), whereas the top of the ridge is drier and more ionically benign. Small-scale variation in ion concentrations $\left(\mathrm{Ca}^{2+}, \mathrm{Mg}^{2+}, \mathrm{Na}^{+}\right.$, and $\left.\mathrm{K}^{+}\right)$and water availability may exert enough divergent selection within this serpentine ridge to maintain differently adapted species (Rajakaruna and Bohm, 1999; O'Dell and Claassen, 2006).

We sought to determine whether the coexistence of $L$. gracilis and $L$. californica could be explained by genetically based differences in habitat affinity. We attempted to isolate the edaphic variables driving divergence between the habitats and asked if soil variables change over time in each region. Finally, we asked whether selection or limited dispersal or both better explains the abrupt boundary between species. We hypothesized that different selection pressures and ecological specialization to soil conditions maintain the stable parapatric distribution of taxa and therefore contribute to habitat isolation. Alternatively, the distributions may appear stable due to the colonization history of the site and limited dispersal of seeds. We investigated these possibilities with a reciprocal transplant experiment across a small serpentine ridge $(50 \times 60 \mathrm{~m})$. We measured soil variables twice a month to quantify the edaphic environment, and we genotyped germinating seedlings across the abrupt species boundary to look for evidence of dispersal.

\section{MATERIALS AND METHODS}

Study system - Lasthenia Cass. is a predominantly Californian genus of 21 taxa (Chan et al., 2001, 2002). The two most widespread members of the genus, $L$. californica DC. ex Lindl. and L. gracilis (DC.) Green, are self-incompatible spring annuals. Lasthenia gracilis was recognized only recently as meriting separate species status from $L$. californica based on molecular phylogenetic work (Chan et al., 2002). The only morphological difference between the two species is a subtle difference in pappus shape: L. gracilis typically has a flared, white pappus, whereas $L$. californica typically has a linear, brownish pappus (Chan et al., 2002). Both species occur on varied substrates, including alkali flats, serpentine soils, open grasslands, oak woodlands, and coastal bluffs (Ornduff, 1966; Rajakaruna and Bohm, 1999). Lasthenia gracilis occurs throughout southern California, whereas L. californica is predominantly found in northern California, but there is a large area of overlap in the ranges of the two species in central California. We have identified at least five sites where $L$. gracilis and $L$. californica grow side by side in sympatry or very close parapatry. At all mixed sites, the species are found on sloping hillsides, with $L$. californica in the lower swale portion of the hill and L. gracilis in the drier upland (J. M. Yost, unpublished data).

Jasper Ridge Biological Preserve (JR), $37^{\circ} 25^{\prime} \mathrm{N}$ and $122^{\circ} 2.5^{\prime} \mathrm{W}$, is one such site where the two species co-occur in close parapatry. JR is a low ridge in the western foothills of the Santa Cruz Mountains at the base of the San Francisco Peninsula, San Mateo County, California. The serpentine ridge occurs at ca. $180 \mathrm{~m}$ in elevation and covers ca. 20 hectares. A fire road runs the length of the ridge and numerous studies (reviewed in Bohm and Rajakaruna, 2006), including ours, have established transects referenced from this road. Our study site occurs entirely to the west of the fire road on the southwest-facing slope of the ridge.

Previous work at Jasper Ridge has documented typical serpentine conditions including low $\mathrm{K}^{+}$concentrations, low $\mathrm{Ca}$ to $\mathrm{Mg}$ ratios, and the presence of heavy metals (Kruckeberg, 1984; Rajakaruna and Bohm, 1999). The presence of high concentrations of $\mathrm{Mg}^{2+}$ in the soil limits the selective uptake of essential $\mathrm{Ca}^{2+}$, resulting in difficult conditions for plant growth (Brady et al., 2005). The top and bottom of the ridge vary continuously in water availability, organic matter, ion concentrations, and heavy metals; yet, no abrupt shift has been observed in soil conditions that can explain the abrupt transition (over only meters) from L. gracilis at the top of the ridge to L. californica at the bottom of the ridge (Rajakaruna and Bohm, 1999).

Soils-We collected a soil sample from each plot from the top $10 \mathrm{~cm}$ of soil every 2 wk from February through May. All soil samples were air dried and sent to A \& L Western Agricultural Laboratories for analysis (Modesto, CA; soil test suite SNB1). Samples were analyzed for cation exchange capacity (CEC), organic matter (OM), estimated nitrogen release (ENR), $\mathrm{pH}$, hydrogen $\left(\mathrm{H}^{+}\right)$, phosphorus (using Bray and Olsen methods), soluble salts, nitrogen $\left(\mathrm{NO}_{3}{ }^{-}\right)$, sulfur $\left(\mathrm{SO}_{4}{ }^{2-}\right)$, and extractable $\mathrm{K}^{+}, \mathrm{Mg}^{2+}, \mathrm{Ca}^{2+}$, and $\mathrm{Na}^{+}(\mathrm{ppm})$. Additionally, every week from November to May, we measured volumetric water content of each plot by averaging three readings taken just outside each plot using a Spectrum Technologies TDR200 soil moisture meter.

Transplants-In April 2009, we collected seed from ca. 20 L. californica individuals from the bottom of the serpentine ridge at JR (between 50-60 m below the fire road) and $20 \mathrm{~L}$. gracilis individuals from the top of the serpentine ridge (between 5-20 $\mathrm{m}$ from the fire road). Before germination, we dipped all seeds in $1 \%$ bleach solution, rinsed them in deionized water, and placed them in petri dishes on wet filter paper. We placed the dishes at $4{ }^{\circ} \mathrm{C}$ to simulate winter conditions, and after $4 \mathrm{~d}$, we moved the dishes to a growth chamber (Conviron E7 Plant Growth Chamber, Winnipeg, Manitoba, Canada) with $12 / 12 \mathrm{~h}$ of light/dark with $18^{\circ} \mathrm{C}$ day and $12^{\circ} \mathrm{C}$ night temperatures. Approximately $2-6 \mathrm{~d}$ later when the radicle appeared, we transferred seedlings to 1-inch germination trays filled with a germination mixture (Sunshine mix \#3 by SunGro Horticulture Canada, Vancouver, British Columbia, Canada). We watered the seedlings as needed to keep the germination mix moist. In mid-February 2010, we transplanted $20-50 \mathrm{~mm}$ tall seedlings into the field. We chose to plant seedlings instead of seeds to ensure that the plants survived through the germination stage. We, therefore, missed any selection acting on the germination phase and future work will address this shortcoming.

Our transplant plots spanned JR Trail Nine. We established four replicate plots $(1 \times 1 \mathrm{~m}) 5 \mathrm{~m}$ from the fire road at the top of the ridge, where L. gracilis occurs, four plots at the bottom of the ridge (58-64 $\mathrm{m}$ from the fire road), where L. californica occurs, and four plots at ca. $48 \mathrm{~m}$ from the fire road, in the transition zone between the two species. We randomly planted eight unrelated individuals of each species in an alternating pattern in each plot and tried to capture natural competitive interactions by not weeding the plots. Plant density in each plot was equivalent to natural densities. We watered the transplanted seedlings once a day for the first $3 \mathrm{~d}$. To exclude the effects of transplant shock, we replaced any plant that died within the first $5 \mathrm{~d}$ with a new seedling.

Once the seedlings were established, we recorded survival every $2 \mathrm{wk}$. At the end of the season (May-June), we measured reproductive output by collecting and counting all flower heads and counting the total number of viable seeds 
produced. Dark, full seeds were considered viable, while white or lighter, deflated seeds were considered inviable (N. Rajakaruna, personal observation).

Dispersal_-In February, March, and April 2011, we identified naturally occurring germinants to species along the $60 \mathrm{~m}$ transect from the fire road to the oak woodland boundary (this corresponds to Transect 1 in Rajakaruna and Bohm, 1999). We sampled a single individual at $0.25-\mathrm{m}$ intervals from 0 to $30 \mathrm{~m}$ and from 50 to $60 \mathrm{~m}$. We sampled more densely (0.2-m intervals) from 30 to $50 \mathrm{~m}$, where the abrupt transition between species has been observed in mature plants. For preflowering seedlings, we collected young leaf tissue for genotyping with species-specific PCR. Starting in March and April, as plants began to flower, we differentiated the species using pappus morphology (Chan et al., 2002). To genotype leaf samples, we took advantage of a fixed 11-bp deletion in the ITS region of rDNA in L. gracilis (Chan et al., 2002) and developed species-specific primers for $L$. californica and $L$. gracilis. ( $L$. californica forward: 5'-AGAACGACCCGTGAACTTGT, reverse: 5'-GGTTGCCCAAAGGGAAGT; L. gracilis forward: 5'-ATAGCAGAACGACCCGTGAA, reverse: 5'-CTCATGGTTGCCCAMGAAC). Genotyping to species required two PCRs - one with L. californica specific primers and one with $L$. gracilis specific primers. We froze leaf tissue prior to DNA extractions. We placed 2-3 mm of leaf tissue in $300 \mu \mathrm{L}$ of a 10\% Chelex solution (Chelex 100, Bio-Rad Laboratories, Hercules, California). We vortexed samples for $10 \mathrm{~s}$, spun them briefly to ensure that plant material was in the solution, and then incubated them at $95^{\circ} \mathrm{C}$ for $20 \mathrm{~min}$. After the incubation step, we vortexed the samples again for $10 \mathrm{~s}$ and briefly centrifuged them to separate contaminants and Chelex beads from the DNA in the supernatant. We diluted the supernatant from the Chelex extraction 1:1 with water and used it directly in the PCR. PCR consisted of $6 \mu \mathrm{L}$ GoTaq Green PCR premix, $1.2 \mu \mathrm{L}$ of each primer at $10 \mu \mathrm{mol} / \mathrm{L}$, and $1 \mu \mathrm{L}$ of diluted Chelex DNA for a total volume of $12 \mu \mathrm{L}$. The PCR program ran at $95^{\circ} \mathrm{C}$ for $1 \mathrm{~min}$, followed by $30 \mathrm{cy}$ cles of $95^{\circ} \mathrm{C}$ for $1 \mathrm{~min}, 55^{\circ} \mathrm{C}$ for $30 \mathrm{~s}$, and $72^{\circ} \mathrm{C}$ for $2 \mathrm{~min}$, and finished with $72^{\circ} \mathrm{C}$ for $7 \mathrm{~min}$. A positive result for one of the primer pairs indicates species identity. Hybrid plants will amplify with both primer pairs (J. M. Yost, unpublished data). Tissue from known species was concurrently extracted and used as positive controls. We binned the genotyping results by meter, resulting in 4-5 individuals per meter. If a meter position contained individuals from both species, we considered it a "mixed" location. Although seedlings begin germinating in November, young Lasthenia seedlings are indistinguishable from other species on the ridge, especially Plantago erecta (Plantaginaceae), and we were therefore unable to sample seedlings before February.

Data analyses-Soil data from each plot from throughout the season were subjected to a principal component analysis to identify the major axes of variation separating the regions. Soil changes through time were analyzed with a series of linear regressions. Differences in the timing of mortality were analyzed with a survival analysis using a log-rank test in the program JMP (ver. 9.0.0, SAS Institute, Cary, North Carolina, USA).

To compare the average fitness of individuals of both species in the three regions of the hillside, we used a hierarchical modeling approach called aster analysis (Shaw et al., 2008). In most studies, overall fitness is calculated as survival multiplied by various components of fitness. Individuals that do not survive introduce many zeros into the distribution of overall fitness values. This nonnormal fitness distribution complicates and violates many traditional statistical tests, such as ANOVA. Nonparametric modeling approaches, such as GLM with a log link function, have also been used to analyze lifetime fitness data, but they are unable to estimate the effects of individual fitness components or fit unique distributions to fitness parameters. Aster models, developed for implementation in R (R Core Development Team, 2008), allow for joint analysis of multiple fitness components that have different underlying distributions (Geyer et al., 2007; Shaw et al., 2008). Therefore, aster modeling provides a biologically and statistically appropriate method for evaluating both overall fitness differences and the individual components of fitness that contribute to total fitness. Our lifetime fitness model contained four fitness components: survival to flowering, number of inflorescences, total number of seeds, and number of viable seeds. We fit a Bernoulli distribution to survival, zero-truncated Poisson distribution to inflorescence production, Poisson distribution to seed set, and Bernoulli distribution to viable seed set. In addition to fitting appropriate distributions to the model parameters, aster analysis accounts for the dependence of one variable on all previous fitness components, a common shortcoming of other analysis methods.

We built a series of nested models to test the effect of species and region on fitness. In a separate modeling effort, we substituted the first two principal components of the soil variables for region to explicitly test for the effect of edaphic conditions on fitness. To obtain PC values for each plot, we averaged soil variables for each plot through time and conducted the PCA on the means. Using a regional model and a soil PC model, we estimated fitness based on two different, biologically meaningful fitness components, the number of viable seeds produced and inflorescence production. We estimated fitness based on inflorescence production because we experimentally moved selfincompatible individuals away from potential mates and we wanted to know how plants might be capable of reproducing if fully pollinated. This latter approach is a more conservative estimate of habitat isolation since it excludes the low probability of encountering compatible pollen for a rare migrant. In both models, aster estimates of the fitness component of interest (viable seed count and inflorescence production) reflect the contribution of all earlier fitness components even though they are not specifically estimated in our models (Shaw et al., 2008).

We used likelihood ratio tests to determine the best-fit models. We then obtained maximum likelihood estimates and standard errors for viable seed set and inflorescence production for each species.

\section{RESULTS}

Edaphic environment-The principal component analysis of 17 soil variables showed a continuous transition in edaphic habitats from the top to the bottom of the ridge. The first and second principal components (PC1 and PC2) explained 32.9\% and $12.9 \%$ of the variation, respectively, for a total of $45.8 \%$ (Table 1, Fig. 1). PC1 described the major differences between regions. The highest loading variable was the $\mathrm{Ca}$ to $\mathrm{Mg}$ ratio, which was much lower at the bottom indicating a habitat deficient in $\mathrm{Ca}^{2+}$ and enriched in $\mathrm{Mg}^{2+}$. The bottom region had more positive values of PC1 indicating more OM, ENR, $\mathrm{Mg}^{2+}, \mathrm{pH}$, CEC, and VWC but lower concentrations of $\mathrm{Ca}^{2+}$ and $\mathrm{K}^{+}$. The top of the ridge had negative values for PC1 indicating a habitat that is high in $\mathrm{Ca}^{2+}, \mathrm{K}^{+}$, but low in $\mathrm{OM}$, ENR, $\mathrm{Mg}^{2+}, \mathrm{pH}$, and $\mathrm{CEC}$. The middle region was intermediate. Linear regressions reveal directional changes in soil variable through time. Those regions of the ridge that experienced significant increases or decreases in a particular soil variable are presented in Table 2. Nonsignificant results are presented in Appendix S1 (see Supplemental Data with the online version of this article).

Survival - Survival analysis showed that there was a significant difference in the timing of mortality between the two species in

TABLE 1. Principal component analysis of soil variation across a serpentine hillside at Jasper Ridge Biological Reserve. Bold values represent loading scores above 0.5 .

\begin{tabular}{lrr}
\hline \hline Soil character & PC1 $(32.9 \%)$ & PC2 $(12.9 \%)$ \\
\hline Volumetric water content & 0.48853 & 0.34497 \\
Organic matter $(\%)$ & $\mathbf{0 . 7 5 7 9 4}$ & 0.21498 \\
Estimated nitrogen release $($ lbs/acre) & $\mathbf{0 . 7 5 4 8 3}$ & 0.21609 \\
pH & $\mathbf{0 . 6 1 0 0 4}$ & -0.03363 \\
Cation exchange capacity $($ meq $/ 100 \times g)$ & $\mathbf{0 . 6 7 6 7 7}$ & -0.29373 \\
Hydrogen $($ meq $/ 100 \times g)$ & -0.49078 & -0.06023 \\
Soluble salts $($ mmhos/cm) & 0.19061 & $\mathbf{0 . 6 1 8 8 1}$ \\
Nitrogen as $\mathrm{NO}_{3}{ }^{-}(\mathrm{ppm})$ & 0.15799 & $\mathbf{0 . 5 3 5 2 0}$ \\
Phosphorus $\left(\mathrm{Bray}^{-p p m)}\right.$ & -0.10495 & $\mathbf{0 . 5 0 7 9 4}$ \\
Phosphorus $(\mathrm{Olsen}-\mathrm{ppm})$ & -0.02619 & 0.37351 \\
Sulfur as $\left(\mathrm{SO}_{4}{ }^{2-}(\mathrm{ppm})\right.$ & 0.30576 & 0.20835 \\
Calcium $(\mathrm{ppm})$ & $\mathbf{- 0 . 6 5 8 8 4}$ & -0.33565 \\
Magnesium $(\mathrm{ppm})$ & $\mathbf{0 . 7 3 6 0 6}$ & -0.26433 \\
Potassium $(\mathrm{ppm})$ & $\mathbf{- 0 . 7 4 6 3 4}$ & 0.07372 \\
Sodium $(\mathrm{ppm})$ & 0.36739 & $-\mathbf{0 . 6 1 9 2 1}$ \\
Ca: $\mathrm{Mg}$ & $\mathbf{- 0 . 9 1 5 9 9}$ & 0.00625 \\
$\mathrm{~K}: \mathrm{Na}$ & $\mathbf{- 0 . 6 8 3 2 3}$ & 0.35666 \\
\hline
\end{tabular}




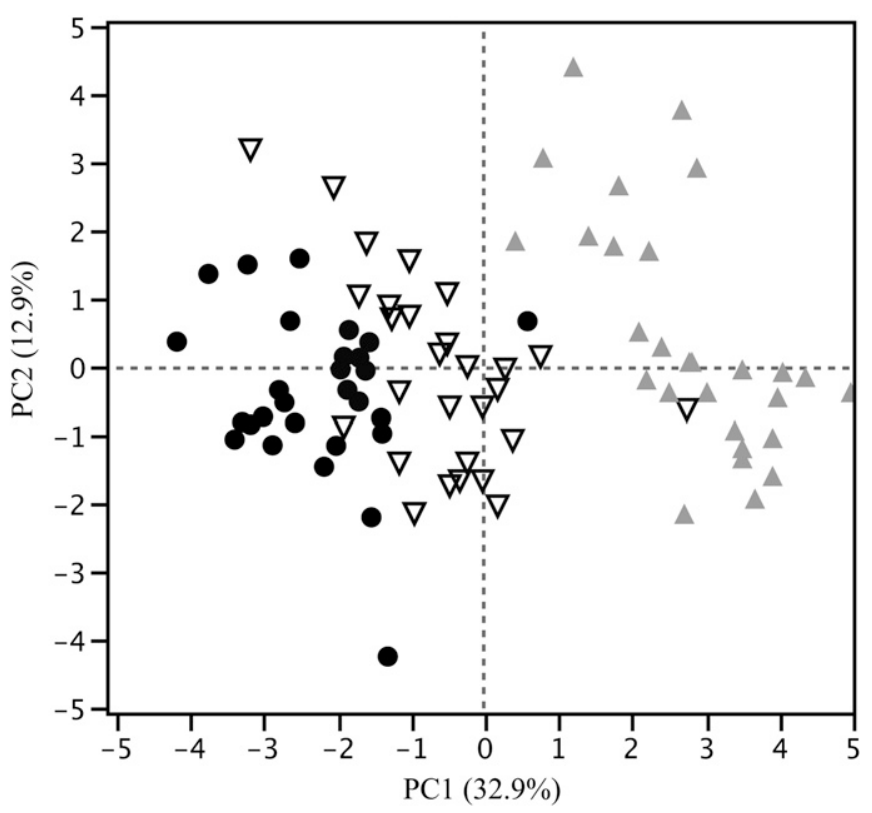

Fig. 1. Principal component analysis of 17 soil variables. The first two principal components (PCs) describe $45.8 \%$ of the variation in soil characteristics among the individual plots at Jasper Ridge. Points represent plot values for the top region (black circles), middle region (open triangles), and bottom region (closed triangles). See Table 1 for loading scores.

the bottom region and the middle region, but not in the top region (Fig. 2). Lasthenia gracilis died earlier than L. californica in the middle region (log-rank, $P=0.0077)$ and in the bottom region (log-rank, $P<0.0001)$.

Overall fitness-We fit two different models to our fitness data (Table 3). In the regional model, we tested for an effect of species and region. The addition of the interaction term species $\times$ region to our model improved the fit significantly (Table 3 ). This is evidence that each species is uniquely adapted to its home site. We estimated fitness using two fitness components, viable seed set and inflorescence production, and we observed the same pattern in each. Therefore, we only show estimates for viable seed set (Fig. 3). Lasthenia californica in its native region produced more inflorescences and set more viable seed than in the other two regions. Lasthenia gracilis reached maximum fitness in the middle region, in both inflorescence production and viable seed set. Each species had a home site advantage in its native region (Fig. 3).

To explicitly test for the effect of edaphic conditions on plant fitness, we ran a separate aster model replacing region for the principal components of soil variables. By using the principal components, we took into account the variation among plots in each region and directly correlated edaphic variation with plant fitness. The model containing only the species $\times \mathrm{PC} 1$ interaction term was the best-fit model and was used for subsequence analyses (Table 3). Adding the three-way interaction term of species $\times \mathrm{PC} 1 \times \mathrm{PC} 2$ was only marginally significant, and we chose not to include it. The significant interaction between PC1 and species indicates that the species are divergently adapted to edaphic factors. Lasthenia gracilis had the highest fitness in plots with the lowest $\mathrm{PC} 1$ values (higher and $\mathrm{K}^{+}$, lower $\mathrm{Mg}^{2+}$ ) (Fig. 4). For L. californica, high fitness was correlated with positive PC1 values (Fig. 4). The same pattern was observed using both viable
TABLE 2. Edaphic changes through time. Linear regression analyses for soils collected every 2 wk at Jasper Ridge. Significant results are presented here. All analyses can be found in Appendix S1 (see Supplemental Data with the online version of this article).

\begin{tabular}{|c|c|c|c|c|}
\hline Soil character & Slope & $r^{2}$ & $F$ & $P$ \\
\hline \multicolumn{5}{|c|}{ Volumetric water content } \\
\hline Top & $-6.02 \mathrm{E}-06$ & 0.45754 & 21.92 & $<0.0001$ \\
\hline Middle & $-5.34 \mathrm{E}-06$ & 0.368494 & 15.17 & 0.0006 \\
\hline \multicolumn{5}{|c|}{ Estimated nitrogen release (lbs/acre) } \\
\hline Top & $1.48 \mathrm{E}-06$ & 0.13634 & 4.1044 & 0.0531 \\
\hline \multicolumn{5}{|c|}{ Phosphorus (Bray-ppm) } \\
\hline Middle & -0.000002 & 0.224788 & 7.5392 & 0.0108 \\
\hline \multicolumn{5}{|c|}{ Phosphorus (Olsen-ppm) } \\
\hline Middle & $-9.64 \mathrm{E}-07$ & 0.132141 & 3.9588 & 0.0572 \\
\hline Bottom & $-1.26 \mathrm{E}-06$ & 0.217246 & 7.2161 & 0.0124 \\
\hline \multicolumn{5}{|c|}{ Magnesium (ppm) } \\
\hline Top & 0.0001165 & 0.409614 & 18.039 & 0.0002 \\
\hline Middle & 0.0001185 & 0.462786 & 22.3979 & $<0.0001$ \\
\hline \multicolumn{5}{|l|}{ Calcium (ppm) } \\
\hline Middle & $6.54 \mathrm{E}-06$ & 0.168258 & 5.2597 & 0.0302 \\
\hline \multicolumn{5}{|l|}{ Sodium (ppm) } \\
\hline Bottom & $1.80 \mathrm{E}-06$ & 0.431419 & 19.7279 & 0.0001 \\
\hline \multicolumn{5}{|c|}{ Cation exchange capacity $(\mathrm{meq} / 100 \times g)$} \\
\hline Top & $1.02 \mathrm{E}-06$ & 0.38298 & 16.138 & 0.0004 \\
\hline Middle & $9.67 \mathrm{E}-07$ & 0.461116 & 22.2478 & $<0.0001$ \\
\hline \multicolumn{5}{|c|}{ Nitrogen as $\mathrm{NO}_{3}^{-}(\mathrm{ppm})$} \\
\hline Top & $-5.62 \mathrm{E}-07$ & 0.180587 & 5.73 & 0.0242 \\
\hline \multicolumn{5}{|l|}{$\mathrm{Ca}: \mathrm{Mg}$ ratio } \\
\hline Top & $-6.49 \mathrm{E}-09$ & 0.329397 & 12.7711 & 0.0014 \\
\hline Middle & $-3.83 \mathrm{E}-09$ & 0.21759 & 7.2307 & 0.0123 \\
\hline Bottom & $-3.06 \mathrm{E}-09$ & 0.224564 & 7.5295 & 0.0109 \\
\hline \multicolumn{5}{|l|}{$\mathrm{K}: \mathrm{Na}$ ratio } \\
\hline Middle & $-1.69 \mathrm{E}-07$ & 0.402039 & 17.4811 & 0.0003 \\
\hline Bottom & $-1.84 \mathrm{E}-07$ & 0.291023 & 10.6725 & 0.0031 \\
\hline
\end{tabular}

seed set and inflorescences production, meaning that the rarity of conspecific mates had only a minor impact, if any, on fitness. We report the results from viable seed set only (Fig. 4).

Dispersal-Our results indicated that L. gracilis and L. californica seedlings occurred from 0-50.0 m and from 43.0-60.0 m along the ridge, respectively. There was a region of overlap between $43.0 \mathrm{~m}$ and $50.0 \mathrm{~m}$ along the ridge; however, there was no observed constriction of the mixed region between February and April as would be expected if late season mortality was responsible for maintaining species distributions. Of over 1000 plants genotyped, only two hybrids were found. These hybrids were collected during the March collection at 31.75 and $36.4 \mathrm{~m}$.

\section{DISCUSSION}

Lasthenia as a genus lacks many of the exciting morphological differences that have motivated other studies of reproductive isolation. Among the 21 taxa in the genus, there are no obvious differences in flower morphology, scent, or color, and flowers are pollinated by a suite of generalist pollinators (Ornduff, 1966; Emery et al., 2012). The discovery of cryptic diversity within the genus and the wide range of edaphic tolerances present in the genus allow us to link more obscure but important mechanisms of ecological divergence, such as physiological tolerance, to reproductive isolation. Here we have investigated the role habitat isolation plays in the parapatric coexistence of 

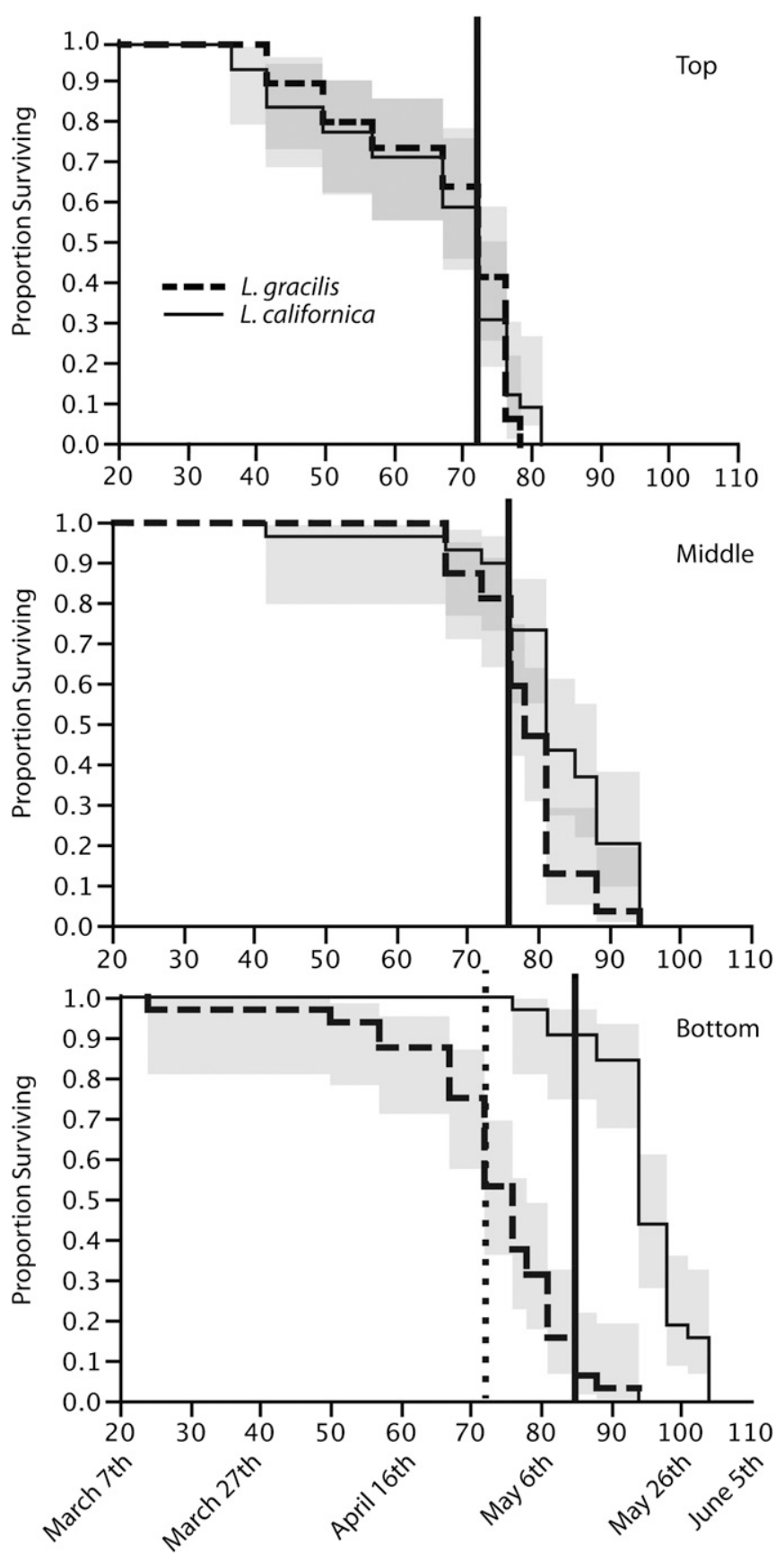

Fig. 2. Survival over time since planting date of the two species in transplanted regions. There was no difference in the timing of mortality between species at the top of the ridge (log-rank, $P=0.9721)$. There is a significant difference in timing of mortality between the species at the middle and bottom of the ridge (log-rank, $P=0.0077$ and $P<0.0001$ ) with L. californica surviving longer in these regions. Shaded regions are pointwise confidence intervals. The vertical solid line indicates peak flowering of $L$. californica. The dotted vertical lines indicates peak flowering of L. gracilis. When only one line is present, peak flowering for both species occurred on the same census date.

L. californica and L. gracilis. The first step in documenting habitat isolation is to show that species are differently adapted. Here we showed that $L$. californica and $L$. gracilis, two cryptic close relatives, can co-occur on a $60 \mathrm{~m}$ serpentine ridge because they are differently adapted to unique edaphic conditions within serpentine soils.

To understand how L. californica and L. gracilis could cooccur in such close proximity, we had to first document potential agents of divergent selection. The close associations plants have with soil implicate edaphic variables as important predictors of plant fitness (Ettema and Wardle, 2002). Our work confirmed that the top, middle, and bottom of the ridge vary continuously in edaphic conditions (Rajakaruna and Bohm, 1999). The most important variables contributing to the differences between the top and bottom of the ridge, as expressed in $\mathrm{PC} 1$, are the $\mathrm{Ca}$ to $\mathrm{Mg}$ ratio, $\mathrm{K}^{+}, \mathrm{OM}$, and ENR. The top of the ridge is drier but more hospitable for plant growth (higher $\mathrm{Ca}^{2+}$ and $\mathrm{K}^{+}$) than the bottom of the ridge, which is wetter, but ionically harsher (high $\mathrm{Mg}^{2+}$ ). We also document dynamic shifts in soil characteristics through time. The bottom region becomes more ionically hostile to plant growth as seen in decreasing $\mathrm{Ca}$ to $\mathrm{Mg}$ and $\mathrm{K}$ to $\mathrm{Na}$ ratios through time. The top and middle regions both undergo significant drying as compared to the bottom region. These changes could have implications for the timing of selection against migrants or maladapted genotypes. While the heterogeneous nature of serpentine soils is gaining appreciation (Kruckeberg, 1984; Baythavong and Stanton, 2010), the implications of this heterogeneity on plant fitness and reproductive isolation are not well understood.

Reciprocal transplant experiments reveal how isolated two taxa might be due to different ecological adaptations. Using aster models we predicted unconditional fitness means using a regional model and a soil PC model. On the basis of fitness estimates in both the regional and soil PC models, if $L$. californica were to disperse uphill (even a distance of $5 \mathrm{~m}$ ) into the L. gracilis region, its fitness would decrease substantially and reach nearly zero at the top of the ridge. When we estimate fitness using inflorescence production, we find the same pattern as observed in the fitness estimates using viable seed set. This indicates that the low fitness of $L$. californica in the middle and top regions of the ridge is not due simply to a lack of successful pollinations. When we isolate the effects of edaphic variation in the soil PC model, L. californica shows a significant positive response in fitness to increasing PC1 values, showing that it is uniquely adapted to the conditions in the bottom region. Predicting plant fitness using PCs takes into account the heterogeneity present within each of our predefined regions, but excludes other biologically important predictors of fitness, such as plant community composition.

Modeling fitness based on region versus PCs resulted in two different patterns for L. gracilis. In the regional model, L. gracilis has maximum fitness in the middle region, whereas the soil PC model shows a negative linear relationship between PC1 and fitness. While PC1 values roughly correspond to our categories of region (top, middle, and bottom; Fig. 1), they do not encompass all of the variation among these categories. Other abiotic or biotic factors must be reducing the fitness of $\mathrm{L}$. gracilis in the top region, such that it has higher fitness in the middle region. Competition with different plant assemblages is a possible explanation (Bischoff et al., 2006). We can, however, conclude that each species is differently adapted to the edaphic extremes found on the ridge, as expressed by PC1. If $L$. gracilis were to disperse downhill, a likely scenario for gravity-dispersed seeds, it would actually have higher fitness toward the middle of the ridge, despite the increasing PC1 values, but only to a point. In the bottom region, $L$. gracilis has low fitness compared to $L$. californica, according to both the regional model and soil 


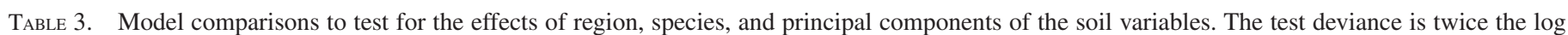
likelihood ratio. Statistical comparisons were made between nested models. A significant analysis of deviance indicates improvement of the model following the addition of a new factor or interaction. Fitness estimates presented in Figs. 3 and 4 are from the best-fit models (in bold).

\begin{tabular}{|c|c|c|c|c|c|}
\hline Model & Model df & Model deviance & Test df & Test deviance & $P$ \\
\hline \multicolumn{6}{|l|}{ Regional model } \\
\hline Species + region & 7 & -92018 & & & \\
\hline Species + region + species $\times$ region & 9 & -92122 & 2 & 104.6 & $<0.0001$ \\
\hline \multicolumn{6}{|l|}{ Soil PC model } \\
\hline Species + PC1 & 6 & -91967 & & & \\
\hline Species + PC1 + PC2 & 7 & -91971 & 1 & 4.221 & 0.03993 \\
\hline Species + PC1 + PC2 + species $\times$ PC1 & 8 & -92030 & 1 & 58.278 & $<0.0001$ \\
\hline Species $+\mathrm{PC} 1+\mathrm{PC} 2+$ species $\times \mathrm{PC} 1+$ species $\times \mathrm{PC} 2$ & 9 & -92031 & 1 & 1.7396 & 0.1872 \\
\hline Species $+\mathrm{PC} 1+\mathrm{PC} 2+$ species $\times \mathrm{PC} 1+$ species $\times \mathrm{PC} 1 \times \mathrm{PC} 2$ & 11 & -92037 & 3 & 7.6574 & 0.05365 \\
\hline
\end{tabular}

PC model. The low fitness of L. gracilis in the bottom region is likely explained by the inability of $L$. gracilis to tolerate higher concentrations of $\mathrm{Mg}^{2+}$ and $\mathrm{Na}^{+}$. This has been experimentally tested in hydroponic studies in which the two species were found to have genetically based differences in their ion physiologies (Rajakaruna et al., 2003b). When grown in ionically extreme conditions, L. californica accumulated more $\mathrm{Mg}^{2+}$, $\mathrm{Na}^{+}$, and $\mathrm{Ca}^{2+}$ in its tissues than did L. gracilis. The inability of L. gracilis to accumulate ions provides a potential mechanism for its low fitness in the bottom region. Ion accumulation is one mechanism plants use to take up water in ionically extreme soils

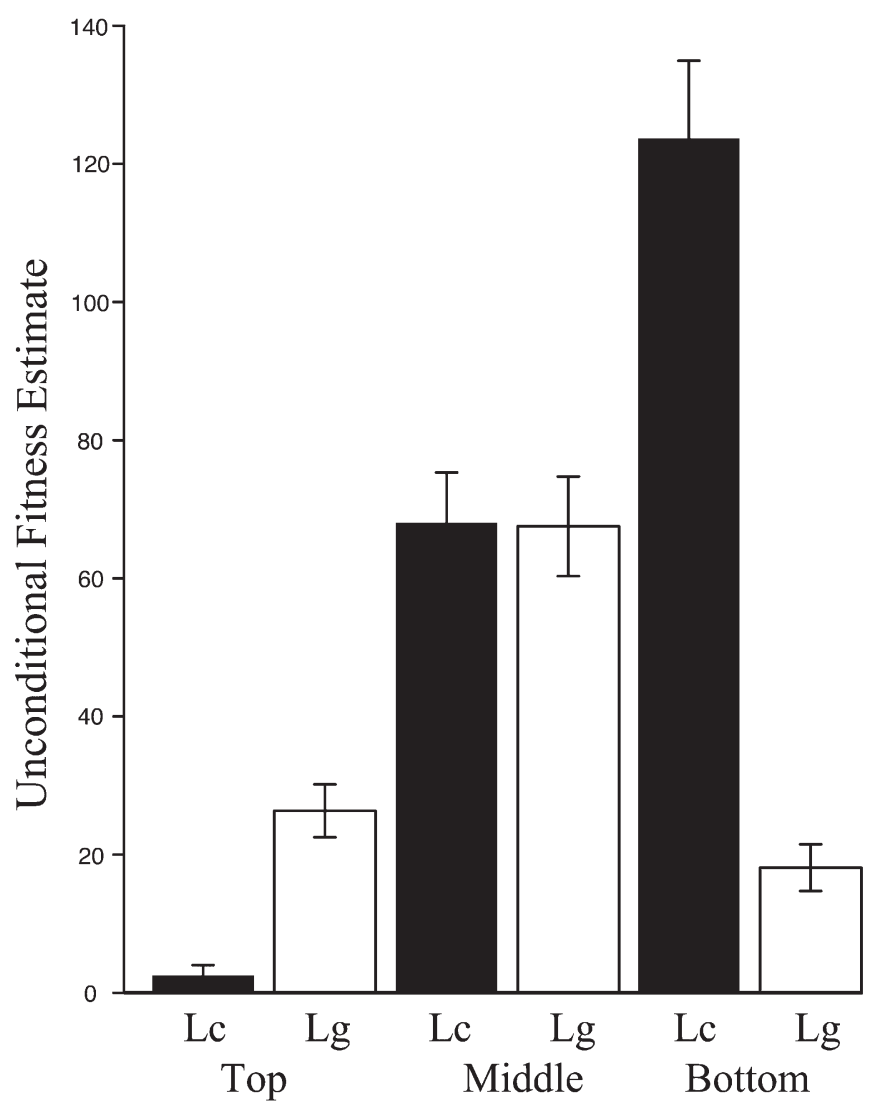

Fig. 3. Unconditional fitness estimates from the aster regional model presented in Table 3. Lasthenia californica (Lc) occurs at the bottom of the ridge and L. gracilis $(\mathrm{Lg})$ occurs at the top of the ridge. Error bars are \pm 1 SE. The same pattern was observed in fitness estimates based on inflorescence production.
(Khan et al., 2000; Rajakaruna et al., 2003a; Ebrahimi and Bhatla, 2011; Nardini et al., 2011). In the transition zone, both models show that L. gracilis and L. californica have equal fitness, likely preventing one species from dominating. We find that regardless of whether we estimate fitness from inflorescence production or viable seed set, both species are at an advantage in their native region.

Initially, we had hoped to correlate the change in soil variables through time with the establishment of the abrupt boundary between the species. Collecting germinating seedlings across the ridge showed that the region of overlap (43-50 m) between the two species is established as early as February. Based on our transplant results, if there was a great amount of seed dispersal, we would expect at least some seeds to survive long enough to flower. However, the dispersal structures on Lasthenia seeds are reduced and are not expected to facilitate long-distance dispersal. We had originally hypothesized that possible migrants would experience late season mortality associated with the onset of the summer drought at the top of the ridge and more concentrated ionic conditions at the bottom. While the top and bottom regions do change in the expected way, our results suggest that the boundary is established much earlier in the season. It is possible that there is seed dispersal followed by early season (pre-February) mortality, which we did not estimate. Additionally, we chose to plant seedlings and therefore missed any selection against the seed/germination phase of the life cycle. Previous greenhouse experiments show that under increasing $\mathrm{Na}^{+}$and $\mathrm{Mg}^{2+}$ concentrations L. gracilis seeds do not germinate as well as L. californica seeds (Rajakaruna et al., 2003b), leading us to conclude that our fitness estimates are conservative.

The narrow habitat use observed at JR is not generally characteristic of L. gracilis and L. californica, since both are known to occur in a wide variety of habitats, including alkali flats, serpentine soils, open grasslands, oak woodlands, and coastal bluffs (Ornduff, 1966; Rajakaruna and Bohm, 1999). It is possible that direct competition between the two species causes them to shift habitat use at sympatric sites, or alternatively, that only those populations with sufficient ecological differences can persist in the same area. We have observed similar habitat partitioning at other mixed sites throughout California. When found together, L. californica is consistently found in lower wetter depressions, and L. gracilis is found on higher hilltops, likely mirroring the difference we found at JR (J. M. Yost, unpublished data). However, the range of habitats in which both species occur at allopatric sites does not appear to follow the pattern observed at sympatric sites (Choe, 2007; J. M. Yost, unpublished data). 


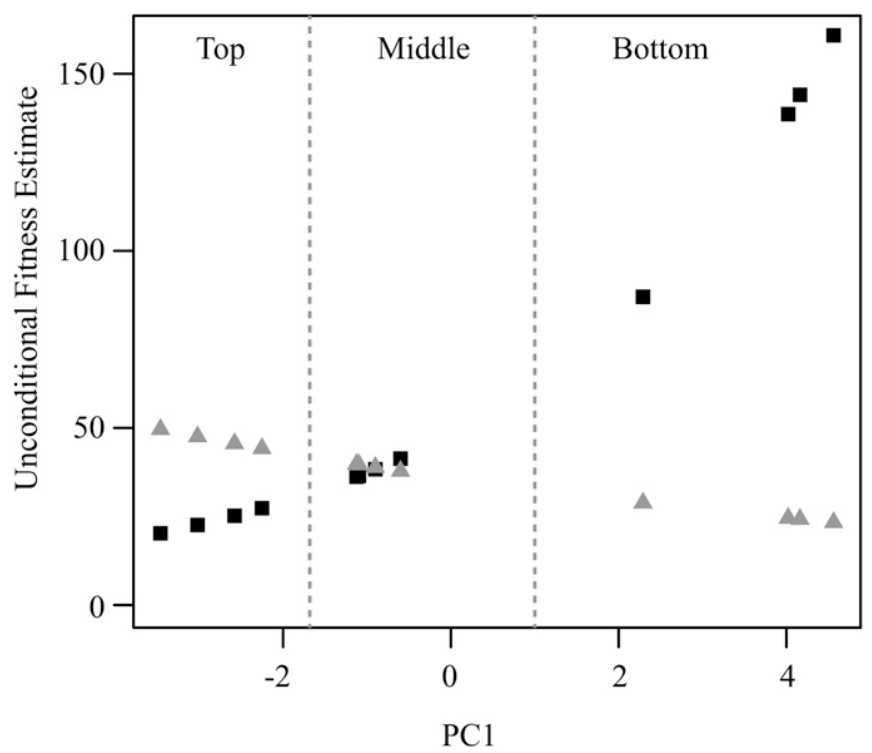

Fig. 4. Unconditional fitness estimates from the aster soil principal components model presented in Table 3. Lasthenia californica (solid squares) occurs at the bottom of the ridge and L. gracilis (gray triangles) occurs at the top of the ridge. The same pattern was observed in fitness estimates based on inflorescence production.

Habitat isolation is only one component of reproductive isolation. This study establishes the role of selection acting against potential migrants at JR, but there is also a documented difference in flowering time of 7-10 d between the top and bottom of the ridge (Rajakaruna and Bohm, 1999). In this case, the earlier drying soils at the top might indirectly cause a shift in flowering time, which further reduces gene flow between the species. Due to the likelihood of shared pollinators at JR, and the overlap of flowering time at the transition zone $(\sim 46 \mathrm{~m})$, there may be postpollination barriers present between the taxa. Preliminary data shows that reduced pollen adhesion and pollen tube growth limit the number of hybrid seeds created (Rajakaruna and Whitton, 2004). Finally, our study did not measure the fitness of hybrid offspring. Even if the hybrids are viable in the greenhouse, the lack of suitable habitat for hybrids, or direct competition with parent taxa, might also function as postzygotic barriers in this system. Our future work will address these possibilities.

Habitat isolation creates a direct link between an organism's ecology and reproductive isolation (Ramsey et al., 2003; Angert and Schemske, 2005; Schemske, 2010; Kay et al., 2011). Recent reviews of plant speciation studies have highlighted the pervasiveness and importance of ecologically based reproductive barriers in general, and habitat isolation specifically (Lowry et al., 2008; Schemske, 2010). Habitat isolation is consistently found to be important between closely related populations or species on and off serpentine soil (Kay et al., 2011), but our work shows that even small-scale heterogeneity within a serpentine outcrop can generate large fitness trade-offs.

Demonstrating that continuous habitats can support differently adapted, yet closely related, taxa is important for a broader understanding of how species are maintained in nature. Detecting divergent adaptation has direct implications for the geographic scale of speciation, as habitat partitioning can contribute to reproductive isolation (Coyne and Orr, 2004; Schemske, 2010; Sobel et al., 2010). While the pervasive role of selection in creating and maintaining species is gaining appreciation (Givnish, 2010; Schemske, 2010; Sobel et al., 2010), this work demonstrates that selection can contribute to reproductive isolation over small spatial scales and continuous environmental gradients.

\section{LITERATURE CITED}

Anacker, B. L., J. B. Whittall, E. E. Goldberg, and S. P. Harrison. 2011 Origins and consequences of serpentine endemism in the California flora. Evolution 65: 365-376.

Angert, A. L., AND D. W. SChemske. 2005. The evolution of species' distributions: Reciprocal transplants across the elevation ranges of Mimulus cardinalis and M. lewisii. Evolution 59: 1671-1684.

Antonovics, J., AND A. D. BRADSHAw. 1970. Evolution in closely adjacent plant populations: 8 . Clinal patterns at a mine boundary. Heredity 25: 349-362.

Baythavong, B. S., and M. L. Stanton. 2010. Characterizing selection on phenotypic plasticity in response to natural environmental heterogeneity. Evolution 64: 2904-2920.

Bischoff, A., L. Cremieux, M. Smilauerova, C. S. Lawson, S. R. Mortimer, J. Dolezal, V. Lanta, et al. 2006. Detecting local adaptation in widespread grassland species-The importance of scale and local plant community. Journal of Ecology 94: 1130-1142.

Bohm, B. A., AND N. RaJAKARUNA. 2006. The Lasthenia californica story: It started with flavonoids. Natural Product Communications 1: 1013-1022.

Brady, K. U., A. R. KRUCKeberg, ANd H. D. Bradshaw. 2005. Evolutionary ecology of plant adaptation to serpentine soils. Annual Review of Ecology, Evolution and Systematics 36: 243-266.

Chan, R., B. G. Baldwin, and R. ORnduff. 2001. Goldfields revisited: A molecular phylogenetic perspective on the evolution of Lasthenia (Compositae: Heliantheae sensu lato). International Journal of Plant Sciences 162: 1347-1360.

Chan, R., B. G. Baldwin, and R. Ornduff. 2002. Cryptic goldfields: A molecular phylogenetic reinvestigation of Lasthenia californica sensu lato and close relatives (Compositae: Heliantheae sensu lato). American Journal of Botany 89: 1103-1112.

Сное, G. 2007. Patterns of edaphic and phenotypic variation in the Lasthenia californica species complex (Asteraceae). Masters thesis, University of British Columbia, Vancouver, British Columbia, Canada.

Clausen, J., D. D. Keck, and W. M. Hiesey. 1941. Regional differentiation in plant species. American Naturalist 75: 231-250.

Coyne, J., And H. A. Orr. 2004. Speciation. Sinauer, Sunderland, Massachusetts, USA

Ebrahimi, R., and S. C. Bhatla. 2011. Effect of sodium chloride levels on growth, water status, uptake, transport, and accumulation pattern of sodium and chloride ions in young sunflower plants. Communications in Soil Science and Plant Analysis 42: 815-831.

Emery, N.C., L.T. Martinez, E. Forrestel, B. G. Baldwin, and D. D. ACKERLY. 2012. The ecology, evolution, and diversification of the vernal pool niche in Lasthenia (Madieae, Asteraceae). In D. G. Alexander and R. A. Schlising [eds.], Research and recovery in vernal pool landscapes, 39-58. Studies from the Herbarium, vol. 16, Chico State University, Chico, California, USA.

Ettema, C. H., AND D. A. WardLE. 2002. Spatial soil ecology. Trends in Ecology \& Evolution 17: 177-183.

GARDNER, M., AND M. MACNAIR. 2000. Factors affecting the co-existence of the serpentine endemic Mimulus nudatus Curran and its presumed progenitor, Mimulus guttatus Fischer ex DC. Biological Journal of the Linnean Society 69: 443-459.

Geyer, C. J., S. Wagenius, and R. G. Shaw. 2007. Aster models for life history analysis. Biometrika 94: 415-426.

Givnish, T. J. 2010. Ecology of plant speciation. Taxon 59: 1326-1366.

Harrison, S., J. H. Viers, AND J. F. Quinn. 2000. Climatic and spatial patterns of diversity in the serpentine plants of California. Diversity \& Distributions 6: 153-161. 
KAWECKI, T. J., AND D. EBERT. 2004. Conceptual issues in local adaptation. Ecology Letters 7: 1225-1241.

KAY, K. M. 2006. Reproductive isolation between two closely related hummingbird pollinated neotropical gingers. Evolution 60: 538-552.

Kay, K. M., K. L. Ward, L. R. Watt, and D. W. Schemske. 2011. Plant speciation. In S. P. Harrison and N. Rajakaruna [eds.], Serpentine: Evolution and ecology in a model system, 71-96. University of California Press, Berkeley, California, USA.

Khan, M. A., I. A. Ungar, AND A. M. Showalter. 2000. Effects of salinity on growth, water relations and ion accumulation of the subtropical perennial halophyte, Atriplex griffithii var. stocksii. Annals of Botany 85: 225-232.

KruckeberG, A. R. 1951. Intraspecific variability in the response of certain native plant species to serpentine soil. American Journal of Botany 38: 408-419.

Kruckeberg, A. R. 1984. California serpentines: Flora, vegetation, geology, soils and management problems. University of California Press, Berkeley, California, USA.

LeImu, R., AND M. FISCHER. 2008. A meta-analysis of local adaptation in plants. PLoS ONE 3: e4010.

Linhart, Y. B., and M. C. Grant. 1996. Evolutionary significance of local genetic differentiation in plants. Annual Review of Ecology and Systematics 27: 237-277.

Lowry, D. B., J. L. Modliszewski, K. M. Wright, C. A. Wu, And J. H. WILLIS. 2008. The strength and genetic basis of reproductive isolating barriers in flowering plants. Philosophical Transactions of the Royal Society of London, B, Biological Sciences 363: 3009-3021.

Matute, D. R., C. J. Novak, and J. A. Coyne. 2009. Temperaturebased extrinsic reproductive isolation in two species of Drosophila. Evolution 63: 595-612.

MAYr, E. 1947. Ecological factors in speciation. Evolution 1: 263-288.

MCNeILly, T. 1968. Evolution in closely adjacent plant populations: 3. Agrostis tenuis on a small copper mine. Heredity 23: 99-108.

McNeIlly, T., AND J. ANTONovics. 1968. Evolution in closely adjacent plant populations: 4. Barriers to gene flow. Heredity 23: 205-220.

NARDINI, A., S. SALleo, AND S. JANSEN. 2011. More than just a vulnerable pipeline: Xylem physiology in the light of ion-mediated regulation of plant water transport. Journal of Experimental Botany 62: 4701-4718.

O’Dell, R. E., and V. P. Claassen. 2006. Serpentine and nonserpentine Achillea millefolium accessions differ in serpentine substrate tolerance and response to organic and inorganic amendments. Plant and Soil 279: 253-269.

O’Dell, R. E., and N. Rajakaruna. 2011. Intraspecific variation, adaptation, and evolution. In S. P. Harrison and N. Rajakaruna [eds.], Serpentine: Evolution and ecology in a model system, 97-137. University of California Press, Berkeley, California, USA.

ORnduFF, R. 1966. A biosystematic survey of the goldfield genus Lasthenia (Compositae: Helenieae). University of California Publications in Botany 40: 1-92.
R Core Development Team. 2008. R: A language and environment for statistical computing 2.8.0. R Foundation for Statistical Computing, Vienna, Austria.

RAJAKARUNA, N. 2003. Edaphic differentiation in Lasthenia: A model for studies in evolutionary ecology. Madroño 50: 34-40.

Rajakaruna, N., AND B. A. Bohm. 1999. The edaphic factor and patterns of variation in Lasthenia californica (Asteraceae). American Journal of Botany 86: 1576-1596.

Rajakaruna, N., G. E. Bradfield, B. A. Bohm, and J. Whitton. 2003 a. Adaptive differentiation in response to water stress by edaphic races of Lasthenia californica (Asteraceae). International Journal of Plant Sciences 164: 371-376.

Rajakaruna, N., M. Y. Siddiei, J. Whitton, B. A. Bohm, and A. D. M. GLAss. 2003b. Differential responses to $\mathrm{Na}^{+} / \mathrm{K}^{+}$and $\mathrm{Ca}^{2+} / \mathrm{Mg}^{2+}$ in two edaphic races of the Lasthenia californica (Asteraceae) complex: A case for parallel evolution of physiological traits. New Phytologist 157: 93-103.

Rajakaruna, N., and J. Whitton. 2004. Trends in the evolution of edaphic specialists with an example of parallel evolution in the Lasthenia californica complex. In Q. C. B. Cronk, I. E. P. Taylor, R. Ree, and J. Whitton [eds.], Plant adaptation: Molecular biology and ecology. 103-110. NRC Research Press, Ottowa, Ontario, Canada.

Ramsey, J., H. D. Bradshaw, and D. W. Schemske. 2003. Components of reproductive isolation between the monkeyflowers Mimulus lewisii and M. cardinalis (Phrymaceae). Evolution 57: 1520-1534.

Sambatti, J. B. M., And K. J. Rice. 2006. Local adaptation, patterns of selection, and gene flow in the Californian serpentine sunflower (Helianthus exilis). Evolution 60: 696-710.

Schemske, D. W. 2010. Adaptation and the origin of species. American Naturalist 176: S4-S25.

SeArCy, K. B., AND M. R. MacNair. 1993. Developmental selection in response to environmental-conditions of the maternal parent in Mimulus guttatus. Evolution 47: 13-24.

Shaw, R. G., C. J. Geyer, S. Wagenius, H. H. Hangelbroek, and J. R. ETTERSON. 2008. Unifying life-history analyses for inference of fitness and population growth. American Naturalist 172: E35-E47.

Sobel, J. M., G. F. Chen, L. R. Watt, and D. W. Schemske. 2010. The biology of speciation. Evolution 64: 295-315.

Sork, V. K., K. A. Stowe, and C. Hochwender. 1993. Evidence for local adaptation in closely adjacent subpopulations of northern red oak (Quercus rubra L.) expressed as resistance to leaf herbivores. American Naturalist 142: 928-936.

van der Putten, W. H., P. C. De Ruiter, T. M. Bezemer, J. A. Harvey, M. WASSEN, AND V. Wolters. 2004. Trophic interactions in a changing world. Basic and Applied Ecology 5: 487-494.

Wright, J. W., M. L. Stanton, and R. Scherson. 2006. Local adaptation to serpentine and non-serpentine soils in Collinsia sparsiflora. Evolutionary Ecology Research 8: 1-21. 